\title{
SEDE DEL COMITÉ OLÍMPICO ESPAÑOL, MADRID-ESPAÑA
}

\author{
(HEADQUARTERS OF THE SPANISH OLIMPIC COMMITEE, MADRID-SPAIN)
}

Rafael de La-Hoz, Arquitecto

ESPAÑA

Fecha de recepción: 25-VII-96

$150-12$

\section{RESUMEN}

Dos conceptos complementarios, el olimpico y el docente, han determinado la arquitectura de este edificio que se erige como una pieza destacada en el contexto circundante. Su caráctery las proporciones clásicas que inspiran el conjunto de la composición se presentan como una clara referencia a los origenes del olimpismo.

\section{SUMMARY}

Two complementary concepts, olympics and educational, have determined the architecture of the headquarters of the Spanish Olimpic Commitee, Madrid. this building is well distinguished of the surrounding area. Its character and classic proportions which suggest the total composition are presented as clear reference to the olympic ideas.

\section{Introducción}

El nuevo edificio del Comité Olímpico Español, inaugurado recientemente, se encuentra situado en una de las zonas de Madrid que más se ha desarrollado en los últimos años desde el punto de vista urbanístico. El solar elegido para su edificación se halla en el eje urbano de Hortaleza, que pone en contacto los cinturones de circunvalación M-40 y M-30. Con motivo de la apertura de la nueva sede social se subrayó, por parte de las autoridades de la capital, su condición de primer paso hacia la proyección de Madrid como futura ciudad olímpica, a partir del 2008.

El lugar donde se levanta el edificio es un amplio bulevar, delimitado por las calles Ayacucho y Arequipa, en un entorno constituido por grandes edificios de viviendas. En este contexto, el encargo recibido por el autor fue el de desarrollar un programa perfectamente especificado desde el punto de vista funcional, pero sin limitación alguna en el orden estético.

El primero de los condicionantes con que se encuentra el arquitecto a la hora de asumir la realización del proyecto estuvo representado por la ausencia de arquitectura y el caos urbanístico circundante. En este sentido, la solución adoptada fue la de concebir un edificio que, al mismo tiempo que se erigiera en pieza destacada dentro del contexto, contibuyese a serenar el entorno.

Asimismo, hubo de conjugar de manera armoniosa la enorme superficie disponible de solar con el reducido programa funcional que deseaba desarrollar el Comité Olímpico Español. Es decir, contrariamente a lo que suele ser habitual en los proyectos de oficinas, donde como consecuencia de la tendencia al gigantismo es preciso atemperar su volumen, en el caso presente éste hubo de ser realzado. De ahí que se persiguiera una elevación de la masa construida que contrarrestara, en lo posible, la excesiva horizontalidad del edificio sin que, en ningún momento, quedase afectada la funcionalidad del inmueble.

El edificio consta de tres plantas: principal, primera y sótano, en las que queda contenido el programa de la sede del Comité Olímpico Español. Éste se desarrolla en los aspectos administrativos, de representación, docente $\mathrm{y}$ científico. 
La composición del edificio está presidida por dos conceptos complementarios: el olímpico y el docente, dado que también se impartirá enseñanza en el mismo. Ambas ideas han determinado un perfil distintivo en la arquitectura proyectada. De ahí que el edificio conjugue modernidad y tradición, como referencia clara a los orígenes del olimpismo y también como homenaje a él. Esta referencia haquedado perfectamente plasmada en el carácter y propor- ción clásicos que inspiran el conjunto de la composición.

Por otra parte, el carácter docente que también debe guardar el centro se ha traducido en una arquitectura abierta y acogedora, que tiene su más claro exponente en el amplio atrio de recepción realizado, que invita a acogerse como refugio de la agresión exterior y crea una atmósfera de reunión y comunicación.
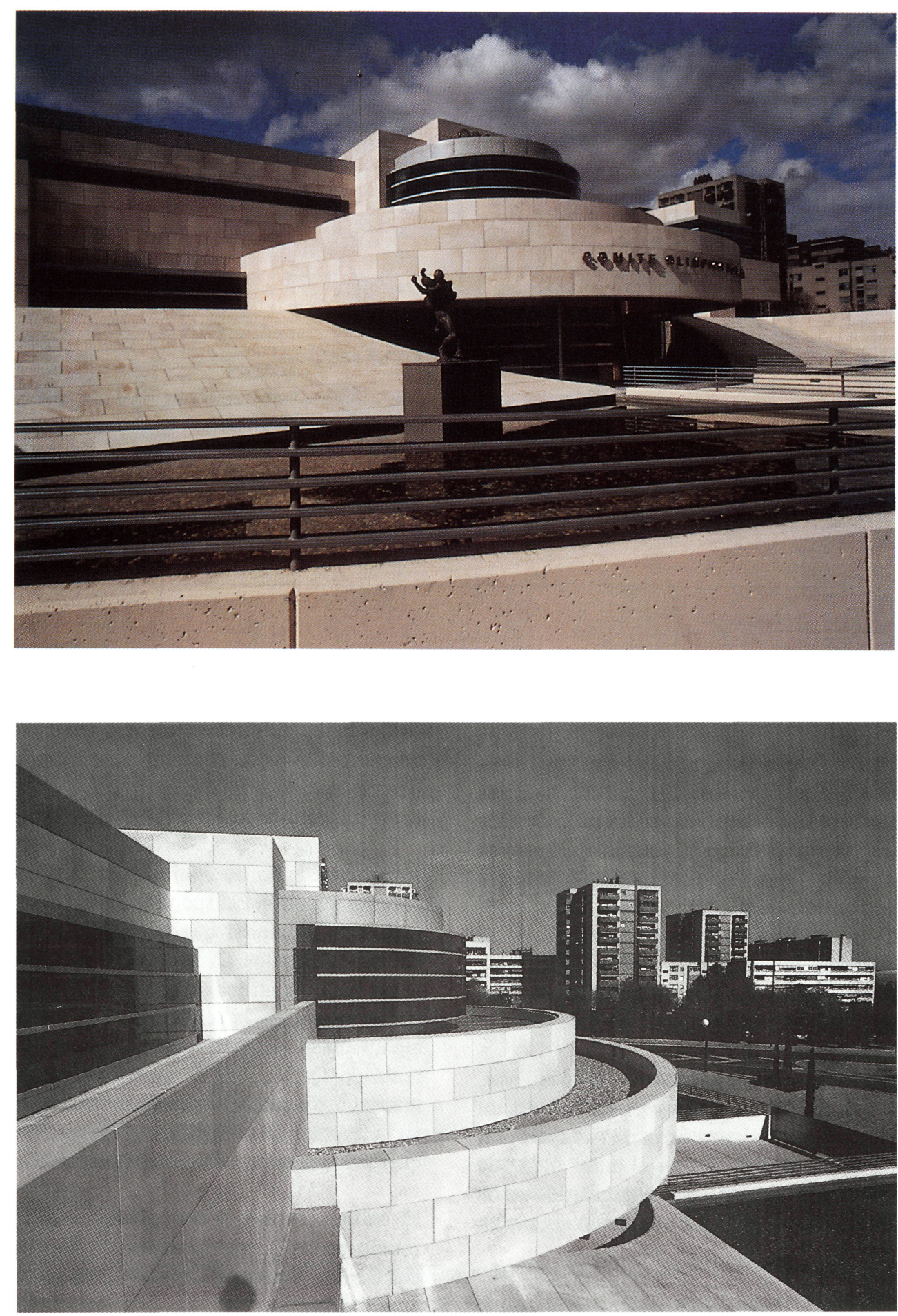

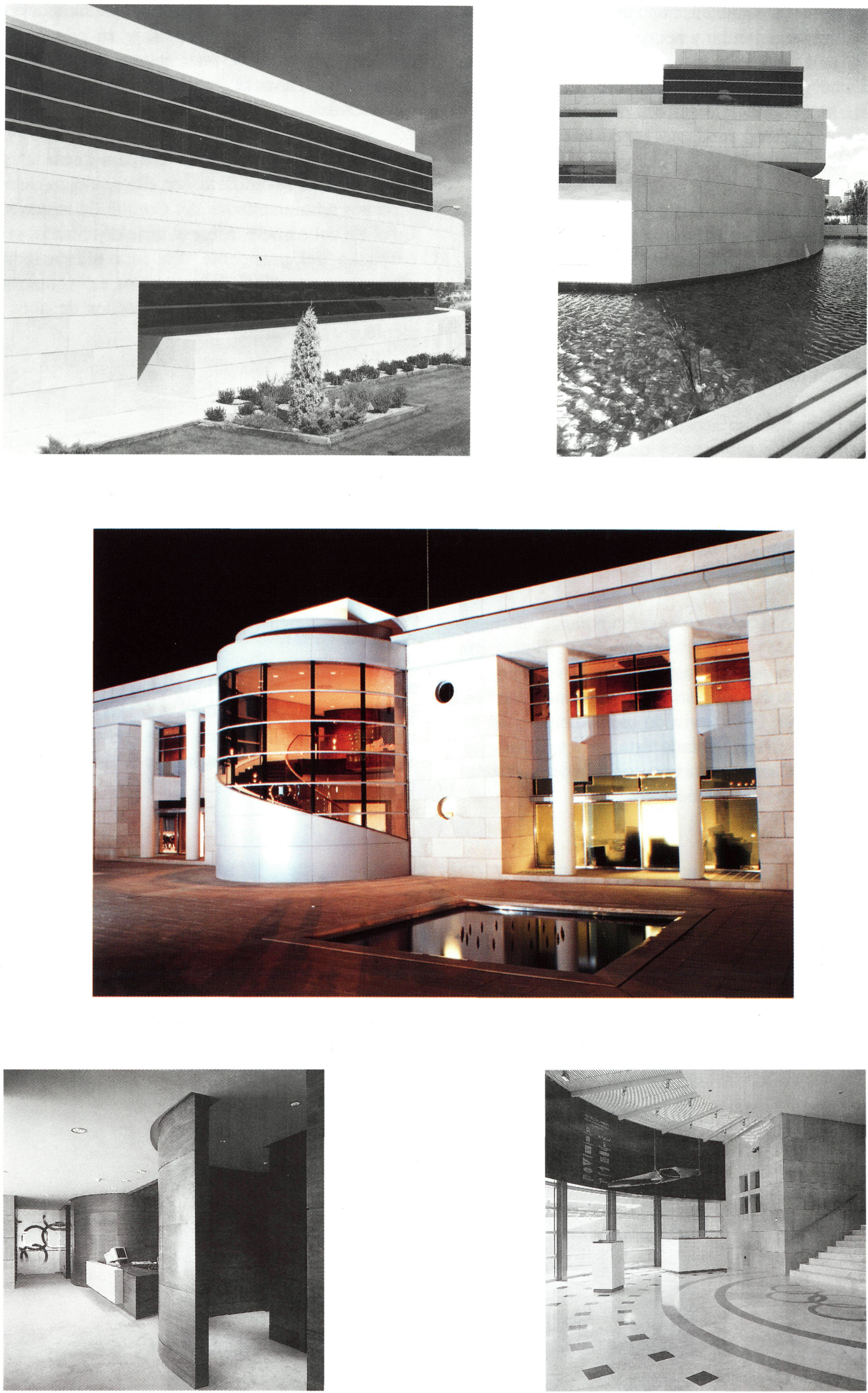

(c) Consejo Superior de Investigaciones Cientificas 
Hay que hacer notar, también, que las circunstancias del solar, su forma semicircular y el hecho de estar bordeado por calles, han dictado a la arquitectura la geometría simétrica que guarda todo el conjunto. Esta solución proporciona los visitantes lafácil comprensión del edificio, lo que es una cualidad fundamental cuando se trata de espacios públicos.

La planta del edificio en forma de "U" permitirá su posterior ampliación. Para un futuroestá prevista la creación en el terreno adyacente a la nueva sede, de un club, un museo e instalaciones educativas y deportivas para todo el olimpismo español.

\section{Descripción del programa}

A la planta principal se accede a través de un amplio vestíbulo que quiere subrayar, y de hecho lo logra, la grandilocuencia del edificio. Desde este espacio, y a través de la amplia escalinata, se accede al vestíbulo principal. Al fondo, el volumen acristalado de la escalera principal domina el conjunto, que se completa con el puesto de información.

A ambos lados, en dos cuerpos bien diferenciados, se sitúan el programa docente y el programa científico. El primero de ellos consta de dos aulas, transformables en una de gran capacidad, y el aula de informática. El programa científico se desarrolla en un laboratorio de biomedición y en la sala de prácticas físicas, dotada ésta de los vestuarios correspondientes. Cuenta, asimismo, con sala de profesores y despachos para técnicos y médicos.
En la planta sótano está ubicado el aparcamiento, con una capacidad para doce vehículos, y en ella se albergan, además, los cuartos de instalaciones y almacenes. Tiene acceso directo a las plantas superiores a través de escalera y ascensor.

Por su parte, en la planta primera recae el carácter representativo del edificio y en ella se alojan, además, los servicios administrativos del Comité Olímpico Español. En el eje del edificio, sobre el atrio de entrada, se sitúa el despacho del presidente. En esta planta también se encuentran estancias representativas, tales como la sala de juntas y la biblioteca y los despachos de altos cargos, técnicos y secretarias.

\section{Materiales}

Los acabados del edificio son los propios de las oficinas: solados de moqueta, tabiquería enlucida y pintada, con mamparas de materiales ligeros. En las zonas más representativas, así como en los aseos, se han empleado empanelados de madera, chapados y solados de mármol o piedra caliza.

Mención aparte merece la utilización de la piedra que se ha realizado en el revestimiento del edificio. Frente al empleo de materiales metálicos, que exigen de una conservación especial, el arquitecto se ha decantado por un material que envejece bien, con elegancia. Además en esta elección ha influido la vinculación que se ha querido establecer entre el edificio y el mundo donde nace el olimpismo, que es un mundo de mármol.

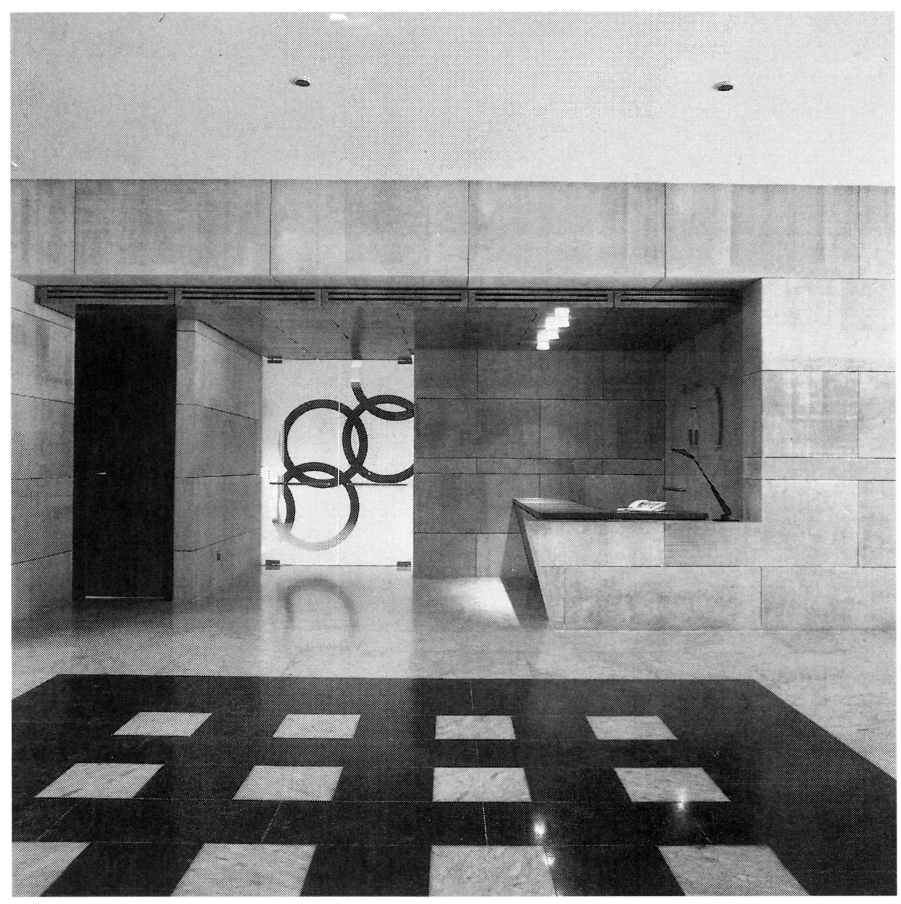



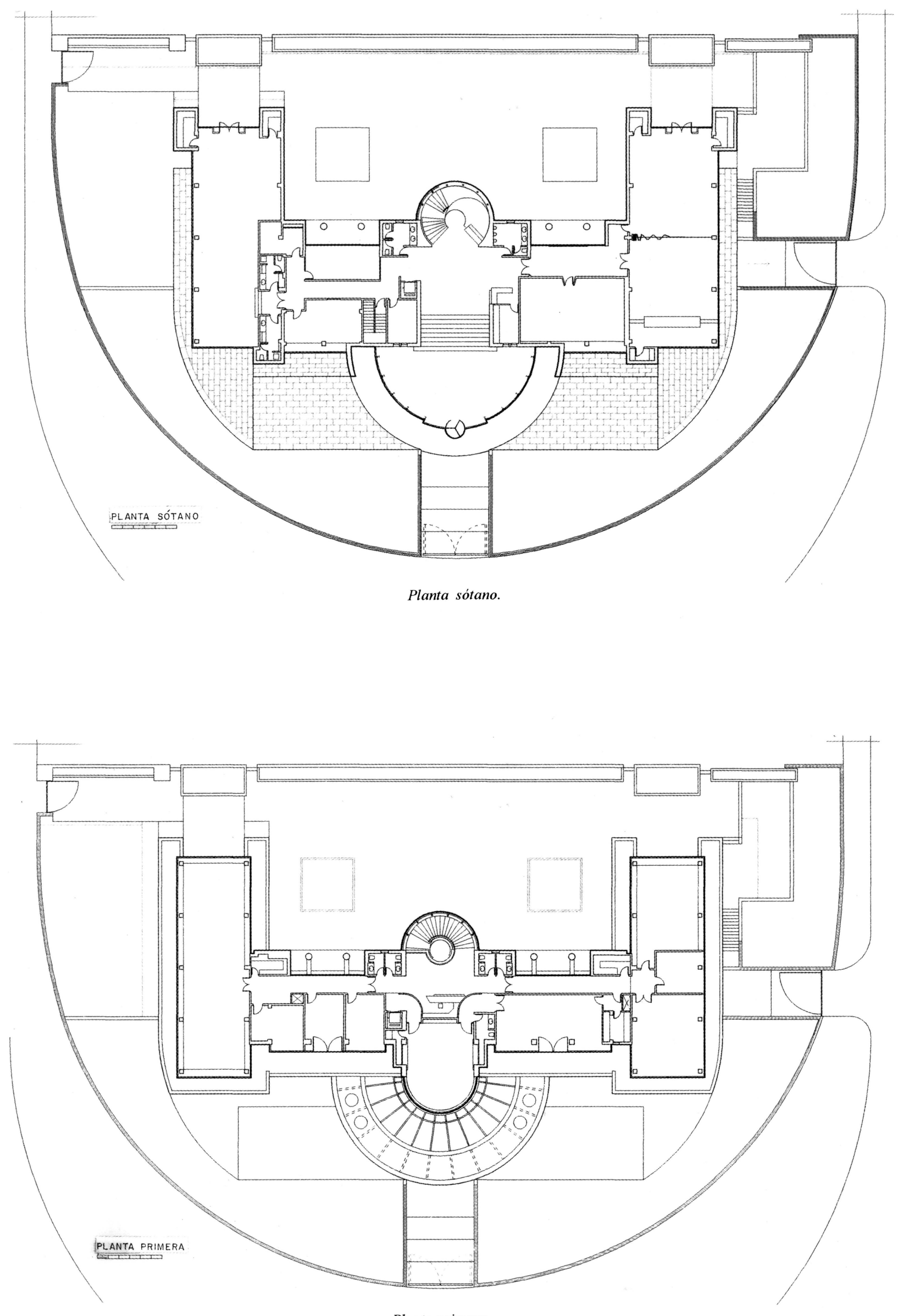

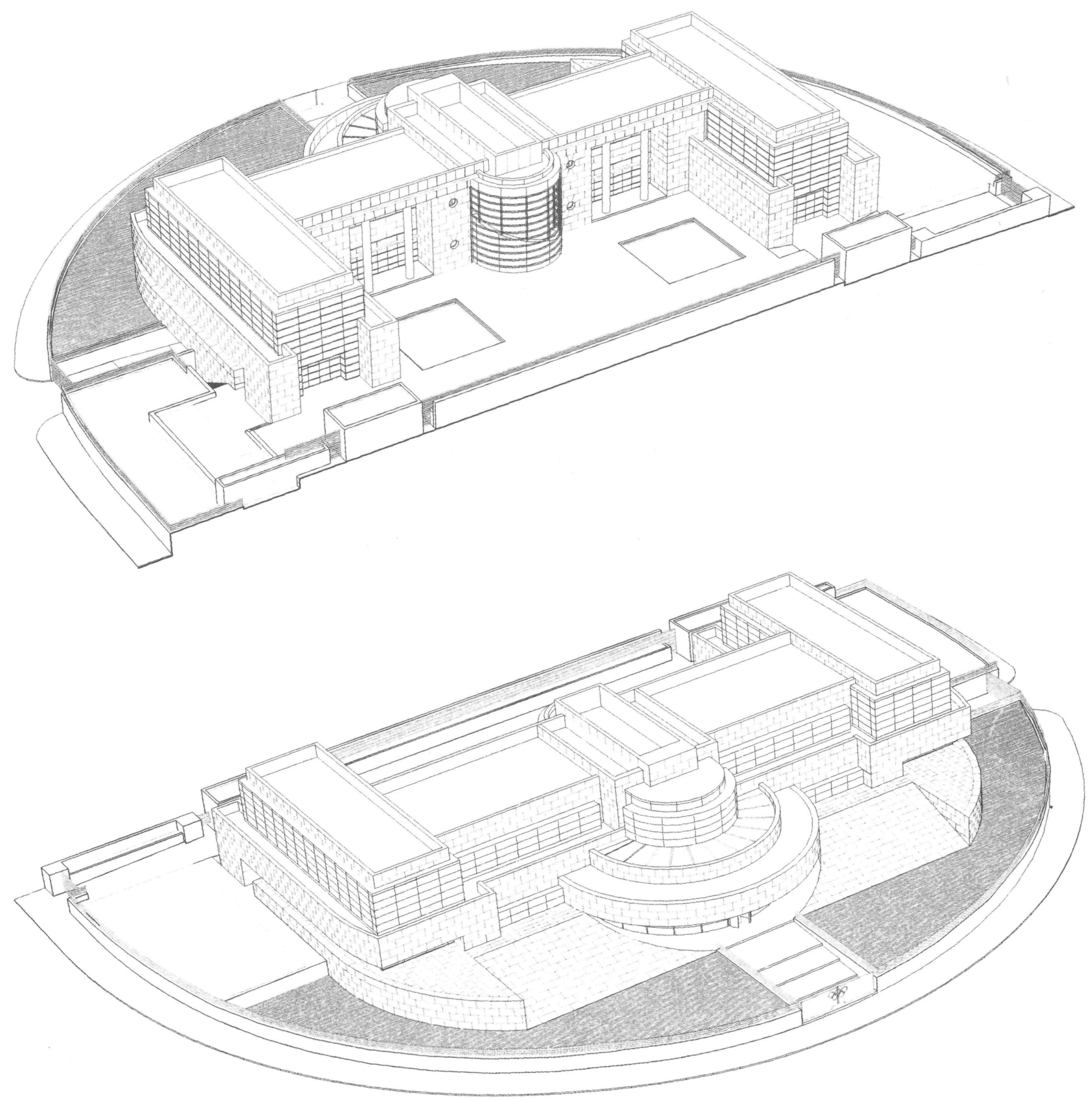

Comité Olímpico Español. Axonométricas.

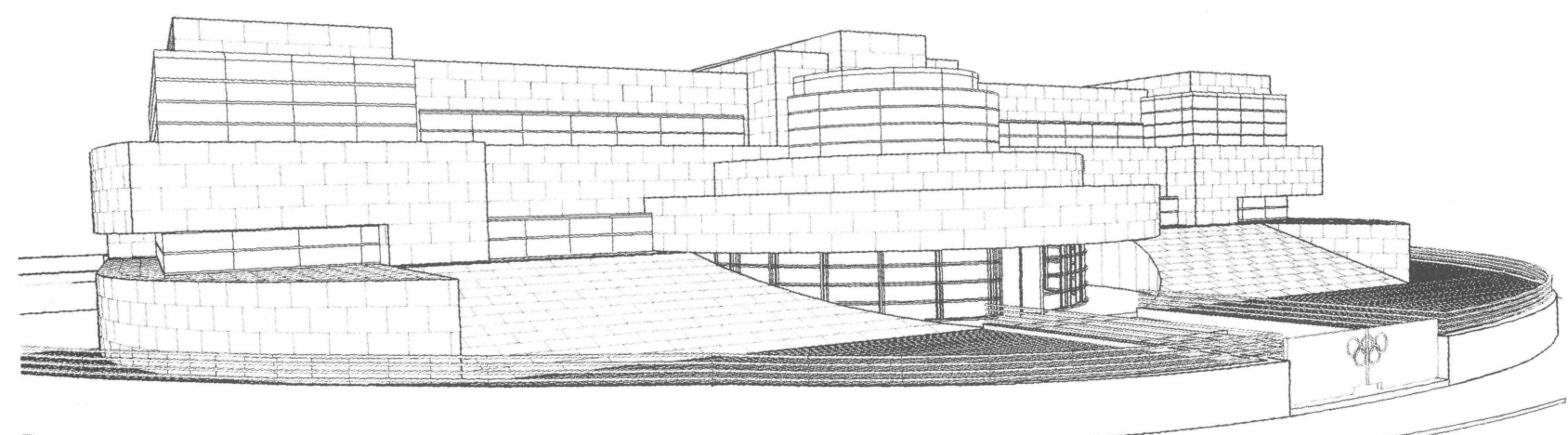




\section{Ficha Técnica}

\section{Comité Olímpico Español}

c/ Ayacucho/Arequipa. Madrid

\section{Promotores}

Fundación del Comité Olímpico Español

\section{Presupuesto final}

300.000.000.-Ptas.

\section{Proyecto}

Rafael de La-Hoz Arquitectos, S.L.

\section{Oficina Técnica Instalaciones}

GOYMAR, S.A.

\section{Dirección de Obra}

Rafael de La-Hoz Castanys. Arquitecto

AVA, S.L. Aparejadores

\section{Ejecución de Obra}

Fomento de Construcciones y Contratas Jefe de Obra: Fernando Paniagua

\section{Decoración}

Cirenia Lamela

Luis de La-Hoz

\section{Empresa Constructora}

Fomento de Construcciones y Contratas

Algunas Empresas Participantes

ALCOTAN: Carpintería de aluminio

SUCOMAGA: Carpintería y revestimientos piedra

AÑOS LUZ: Iluminación

IP7: Central de Seguridad

TAMPA: Jardinería

IMTEMPER: Impermeabilización

TCM: Carpintería de madera

MONFICAR: Mobiliario de madera

ITESA: Instalación eléctrica

WENCESLAO: Pinturas. 